ОБГРУНТУВАННЯ СКЛАДОВИХ НАЦІОНАЛЬНОГО ПЕРЕЛІКУ ЛІКАРСЬКИХ ЗАСОБІВ ВІТЧИЗНЯНОГО ВИРОБНИЦТВА ДЛЯ ФАРМАЦЕВТИЧНОГО ЗАБЕЗПЕЧЕННЯ ПОСТРАЖДАЛИХ ОСІБ В УМОВАХ ОСОБЛИВОГО ПЕРІОДУ В УКРАЇНІ

\title{
SUBSTANTIATION OF COMPONENTS OF THE NATIONAL LIST OF MEDICINES OF DOMESTIC PRODUCTION FOR PHARMACEUTICAL PROVISION OF AFFECTED PERSONS IN CONDITIONS OF THE SPECIAL PERIOD IN UKRAINE
}

Андрій Гудзенко (Andrii Gudzenko) ${ }^{1}$

1 Харківська Медична Академія Післядипломної Освіти, Харків, Україна (Kharkiv Medical Academy of Postgraduate Education, Kharkiv, Ukraine)

*Corresponding author: Andrii Gudzenko, affiliated to Kharkiv Medical Academy of Postgraduate Education, Kharkiv, Ukraine

Abstract. The organizational, legal and marketing characteristics of domestically produced medicines for pharmaceutical provision of affected persons in emergency situations in Ukraine have been studied. The results of the study can be used to approve and further improve the National List of domestic drugs for pharmaceutical provision of various contingents of
Received: August 16, 2021

Published: August 30, 2021 affected persons during special period. The necessity of further researches in the direction of pharmaceutical maintenance of victims in the conditions of the special period in Ukraine was substantiated.

Keywords: organization and management of pharmacy, pharmaceutical provision, special period, affected persons.

Вступ. У попередніх дослідженнях було доведено про важливість судовофармацевтичних досліджень при вивченні фармацевтичного забезпечення постраждалих контингентів пацієнтів із захворюваннями на рівні ЦНС $[1,2]$

Одночасно в ході організаційно-правових досліджень було звернено увагу на особливості обігу антипсихотичних лікарських засобів для фармацевтичного забезпечення пацієнтів із коморбідними розладами, що має особливе значення для фармацевтичного забезпечення постраждалих осіб в умовах особливого періоду [3, 4].

Мета. Обгрунтування складових національного переліку лікарських засобів для фармацевтичного забезпечення постраждалих контингентів населення в умовах особливого періоду в Україні шляхом вивчення 
організаційно-правових та маркетингових характеристик лікарських засобів вітчизняних виробників.

Матеріали та методи. Матеріалами дослідження були державні нормативно-правові акти щодо фармацевтичного забезпечення постраждалих категорій осіб, регулювання обігу вказаних лікарських засобів, інструкції для медичного застосування, клінічні протоколи лікування. Для проведення дослідження було використано методики та методи організаційно-правового, судово-фармацевтичного, нормативного, документального та графічного аналізу.

Результати та ï обговорення. В ході дослідження було вивчено асортимент лікарських засобів, необхідних для фармацевтичного забезпечення постраждалих осіб в умовах надзвичайних ситуацій особливого періоду та систематизовано 300 препаратів вітчизняних виробників України. На наступному етапі дослідження було проаналізовано маркетингові характеристики лікарських засобів за кодами АТС, кількістю за номенклатурою вітчизняних виробників, МНН та вітчизняними виробниками для фармацевтичного забезпечення постраждалих осіб в умовах особливого періоду станом на 01.01.2020 р., що приведено у табл. 1.

Таблиця 1. Маркетингові характеристики лікарських засобів для фармацевтичного забезпечення постраждалих в умовах надзвичайних ситуацій в Україні.

\begin{tabular}{|c|c|c|c|c|c|c|c|}
\hline & Код АТС-класифікації & $\begin{array}{r}\text { Номенк } \\
\text { вітчизг } \\
\text { виробг }\end{array}$ & $\begin{array}{l}\text { атура } \\
\text { них } \\
\text { iкiв }\end{array}$ & $\mathrm{MH}$ & & $\begin{array}{l}\text { Вітчиз } \\
\text { виробг }\end{array}$ & ині \\
\hline & & Кількість & $\%$ & Кількість & $\%$ & Кількість & $\%$ \\
\hline A & $\begin{array}{l}\text { Засоби, що впливають на } \\
\text { систему травлення та } \\
\text { метаболізм }\end{array}$ & 58 & 19,46 & 18,67 & 18,7 & 8 & 13,33 \\
\hline B & $\begin{array}{l}\text { Засоби, що впливають на } \\
\text { систему крові та гемопоез }\end{array}$ & 5 & 1,68 & 1,66 & 1,7 & 3 & 5,00 \\
\hline $\mathrm{C}$ & $\begin{array}{l}\text { Засоби, що впливають на } \\
\text { серцево-судинну систему }\end{array}$ & 53 & 17,79 & 16,18 & 16,2 & 6 & 10,00 \\
\hline $\mathrm{D}$ & Дерматологічні засоби & 33 & 11,07 & 11,62 & 11,6 & 6 & 10,00 \\
\hline $\bar{G}$ & $\begin{array}{l}\text { Засоби, що впливають на } \\
\text { сечостатеву систему і } \\
\text { статеві гормони }\end{array}$ & 3 & 1,01 & 1,24 & 1,2 & 3 & 5,00 \\
\hline $\mathrm{H}$ & $\begin{array}{l}\text { Препарати гормонів для } \\
\text { системного застосування } \\
\text { (окрім статевих гормонів та } \\
\text { iнсулінів) }\end{array}$ & 5 & 1,68 & 2,07 & 2,1 & 1 & 1,67 \\
\hline $\mathrm{J}$ & $\begin{array}{l}\text { Протимікробні засоби для } \\
\text { медичного застосування }\end{array}$ & 37 & 12,42 & 13,28 & 13,3 & 5 & 8,33 \\
\hline $\mathrm{L}$ & $\begin{array}{l}\text { L Антинеопластичні та } \\
\text { імуномодулюючі засоби }\end{array}$ & 1 & 0,34 & 0,41 & 0,4 & 1 & 1,67 \\
\hline $\mathrm{M}$ & $\begin{array}{l}\text { Засоби, що впливають на } \\
\text { опорно-руховий апарат }\end{array}$ & 21 & 7,05 & 7,05 & 7,1 & 7 & 11,67 \\
\hline
\end{tabular}


SSP Modern Pharmacy and Medicine (ISSN 2733-368X), Volume 1 Issue 1 August 2021

\begin{tabular}{|c|c|c|c|c|c|c|c|}
\hline $\mathrm{N}$ & $\begin{array}{l}\text { Засоби, що діють на нервову } \\
\text { систему }\end{array}$ & 57 & 19,13 & 19,09 & 19,1 & 9 & 15,00 \\
\hline $\mathrm{P}$ & $\begin{array}{l}\text { Протипаразитарні засоби, } \\
\text { інсектициди і репеленти }\end{array}$ & 5 & 1,68 & 1,24 & 1,2 & 4 & 6,67 \\
\hline $\mathrm{R}$ & $\begin{array}{l}\text { Засоби, що діють на } \\
\text { респіраторну систему }\end{array}$ & 18 & 6,04 & 6,64 & 6,6 & 5 & 8,33 \\
\hline $\mathrm{S}$ & $\begin{array}{l}\text { Засоби, що діють на органи } \\
\text { чуття }\end{array}$ & - & & & - & - & \\
\hline $\mathrm{V}$ & Різні засоби & 2 & 0,67 & 0,83 & 0,8 & 2 & 3,33 \\
\hline & Всього & 298 & 100 & 241 & 100 & 60 & 100 \\
\hline
\end{tabular}

Джерело: власна розробка

Дані табл. 1 свідчать, що серед лікарських засобів для фармацевтичного забезпечення постраждалих в умовах особливого періоду в Україні за номенклатурою вітчизняних виробників превалює клініко-фармакологічна група АТС-коду А «Засоби, що впливають на систему травлення та метаболізм» (19,46\%), за МНН і вітчизняним виробником - АТС-код N «Засоби, що діють на нервову систему» (відповідно 19,09\% і 15,00\%).

Організаційно-правові характеристики лікарських засобів було вивчено за трьома показниками доступності режиму контроля: клініко-фармакологічна, класифікаційно-правова та номенклатурно-правова. Клініко-фармакологічна характеристика лікарських засобів торкалася визначення коду АТCкласифікації, класифікаційно-правова - безпеки дії лікарських засобів на організм пацієнта, а номенклатурно-правова - форми відпуску лікарських засобів (за рецептом або без рецепта) [5-8].

Результати дослідження класифікаційно-правової характеристики лікарських засобів для фармацевтичного забезпечення постраждалих в умовах надзвичайних ситуацій представлено в табл. 2.

Таблиця 2. Класифікаційно-правова характеристика лікарських засобів для фармацевтичного забезпечення постраждалих в умовах особливого періоду в Україні.

\begin{tabular}{|l|c|c|c|c|c|c|}
\hline $\begin{array}{c}\text { Код АТС- } \\
\text { класифікації }\end{array}$ & $\begin{array}{c}\text { Загальна } \\
\text { група Л3 }\end{array}$ & $\begin{array}{c}\text { Наркотичні } \\
\text { Л3 }\end{array}$ & $\begin{array}{c}\text { Психотропні } \\
\text { Л3 }\end{array}$ & $\begin{array}{c}\text { Сильнодіючі } \\
\text { Л3 }\end{array}$ & $\begin{array}{c}\text { Отруйні } \\
\text { Л3 }\end{array}$ & Всього \\
\hline $\mathrm{A}$ & 58 & - & - & - & - & 58 \\
\hline $\mathrm{B}$ & 5 & - & - & - & - & 5 \\
\hline $\mathrm{C}$ & 53 & - & - & - & - & 53 \\
\hline $\mathrm{D}$ & 33 & - & - & - & - & 33 \\
\hline $\mathrm{G}$ & 3 & - & - & - & - & 3 \\
\hline $\mathrm{H}$ & 5 & - & - & - & - & 5 \\
\hline $\mathrm{J}$ & 37 & - & - & - & - & 37 \\
\hline $\mathrm{L}$ & 1 & - & - & - & - & 1 \\
\hline $\mathrm{M}$ & 21 & - & - & - & - & 21 \\
\hline $\mathrm{N}$ & 48 & 2 & 5 & 1 & 1 & 57 \\
\hline $\mathrm{P}$ & 5 & - & - & - & - & 5 \\
\hline $\mathrm{R}$ & 17 & 1 & - & - & - & 18 \\
\hline $\mathrm{S}$ & - & - & - & - & - & - \\
\hline $\mathrm{V}$ & 2 & - & - & - & - & 2 \\
\hline
\end{tabular}


SSP Modern Pharmacy and Medicine (ISSN 2733-368X), Volume 1 Issue 1 August 2021

\begin{tabular}{|l|l|l|l|l|l|l|}
\hline Разом & 288 & 3 & 5 & 1 & 1 & 298 \\
\hline
\end{tabular}

Джерело: власна розробка

3 табл. 2 видно, що в Україні серед лікарських засобів вітчизняного виробництва для фармацевтичного забезпечення постраждалих в умовах надзвичайних ситуацій більшість лікарських засобів (288) відноситься до загальної класифікаційно-правової групи. Проте, слід зазначити, що сукупність лікарських засобів коду N АТС-класифікації (засоби, що діють на нервову систему), крім Л3 загальної групи (84,2\%), становлять психотропні лікарські засоби $(8,7 \%)$, наркотичні лікарські засоби $(3,5 \%)$, сильнодіючі і отруйні (однаково по 1,8\%). Наркотичні лікарські засоби також зустрічаються серед лікарських засобів, що діють на респіраторну систему (код R).

При вивченні номенклатурно-правової характеристики (Табл. 3) лікарських засобів для фармацевтичного забезпечення постраждалих в умовах надзвичайних ситуацій було встановлено, що 55,7\% складають рецептурні лікарські засоби, а 44,3\% - безрецептурні.

Таблиця 3. Номенклатурно-правова характеристика лікарських засобів для фармацевтичного забезпечення постраждалих в умовах особливого періоду.

\begin{tabular}{|c|c|c|c|c|c|}
\hline \multirow[t]{2}{*}{$\begin{array}{c}\text { Код АТС- } \\
\text { класифікації }\end{array}$} & \multicolumn{2}{|c|}{ Рецептурні лікарські засоби } & \multicolumn{2}{|c|}{$\begin{array}{c}\text { Безрецептурні лікарські } \\
\text { засоби }\end{array}$} & \multirow[t]{2}{*}{ Всього } \\
\hline & Кількість & $\%$ & Кількість & $\%$ & \\
\hline A & 15 & 9,04 & 43 & 32,58 & 58 \\
\hline B & 3 & 1,81 & 2 & 1,52 & 5 \\
\hline $\mathrm{C}$ & 39 & 23,49 & 14 & 10,61 & 53 \\
\hline $\mathrm{D}$ & 9 & 5,42 & 24 & 18,18 & 33 \\
\hline $\mathrm{G}$ & - & & 3 & 2,27 & 3 \\
\hline $\mathrm{H}$ & 4 & 2,41 & 1 & 0,76 & 5 \\
\hline $\mathrm{J}$ & 35 & 21,08 & 2 & 1,52 & 37 \\
\hline $\mathrm{L}$ & - & & 1 & 0,76 & 1 \\
\hline $\mathrm{M}$ & 12 & 7,23 & 9 & 6,82 & 21 \\
\hline $\mathrm{N}$ & $\begin{array}{c}41 \text { (в т.ч. } 2 \text { лише } \\
\text { фарм. та мед. } \\
\text { установам) }\end{array}$ & 24,70 & 16 & 12,12 & 57 \\
\hline $\mathrm{P}$ & 2 & 1,20 & 3 & 2,27 & 5 \\
\hline $\mathrm{R}$ & 6 & 3,61 & 12 & 9,09 & 18 \\
\hline $\mathrm{S}$ & - & - & - & & - \\
\hline $\mathrm{V}$ & - & - & 2 & 1,52 & 2 \\
\hline Всього: & 166 & 100 & 132 & 100 & 298 \\
\hline
\end{tabular}

Джерело: власна розробка

Більш детальний спектр рецептурних і безрецептурних лікарських засобів за кодами АТС-класифікації зображено на рис. 1 та 2 відповідно. Зокрема серед рецептурних лікарських засобів для фармацевтичного забезпечення постраждалих в умовах надзвичайних ситуацій переважають засоби, що діють на нервову систему (код N) $-24,70 \%$ і засоби, що впливають на серцевосудинну систему (код С) - 23,49\%. В свою чергу, більшість серед 
безрецептурних лікарських засобів становлять засоби, що впливають на систему травлення та метаболізм (код А) $-32,58 \%$ і дерматологічні засоби (код D) $-18,18 \%$.

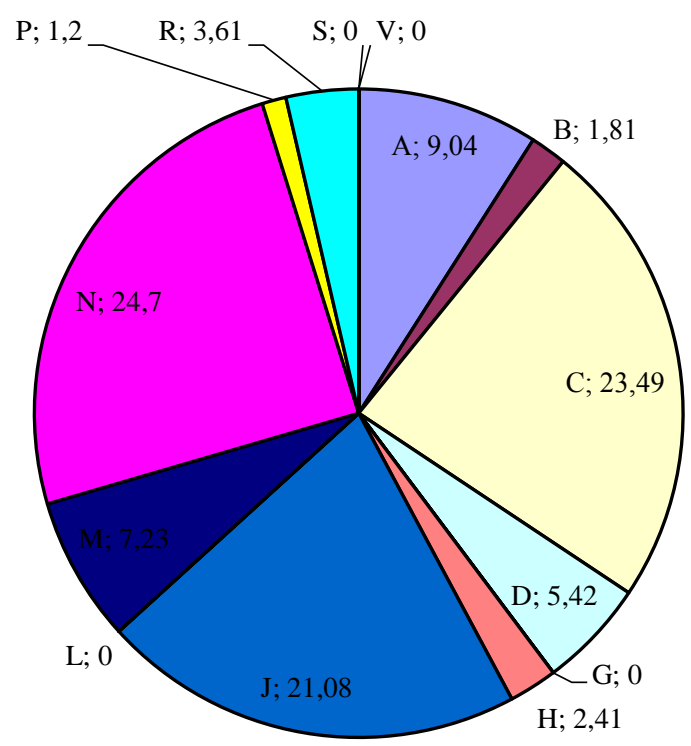

Рис. 1. Спектр рецептурних лікарських засобів за кодами АТCкласифікації.

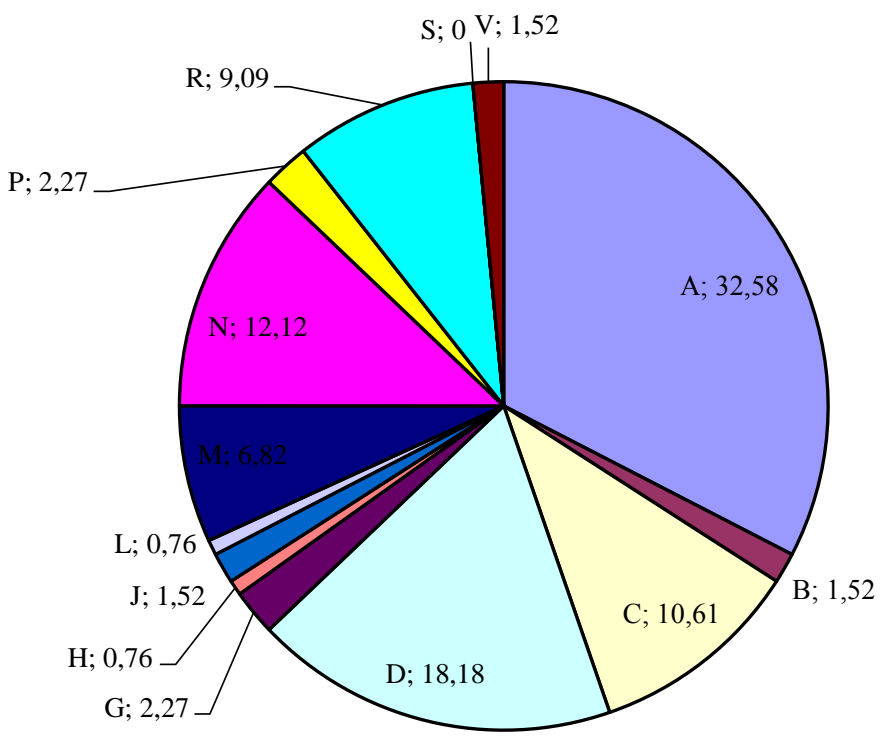

Рис. 2. Спектр безрецептурних лікарських засобів за кодами АТСкласифікації.

Висновки. Досліджено організаційно-правові та маркетингові характеристики лікарських засобів вітчизняного виробництва для фармацевтичного забезпечення постраждалих в умовах надзвичайних ситуацій в Україні. Результати дослідження можуть бути використані для затвердження Національного переліку лікарських засобів вітчизняного виробництва для 
фармацевтичного забезпечення різних контингентів постраждалих категорій населення в умовах особливого періоду. Подальші дослідження у напрямку оптимізації фармацевтичного забезпечення постраждалих осіб тривають.

Автор висловлює вдячність кафедрі медичного та фармацевтичного права, загальної і клінічної фармачї (завідувачка - проф. Шаповалова В.О.) Харківської медичної академії післядипломної освіти за сприяння та допомогу у проведенні дослідження.

\section{Список літератури.}

1. Concerning the importance of forensic and pharmaceutical researches to improve patients' accessibility to medicines / V. Shapovalov, A. Gudzenko, L. Komar, A. Butko, V. Shapovalova, V.Shapovalov. Pharmacia. 2017. Vol. 65. N. 2. P. 23-29.

2. Forensic and pharmaceutical study of the presence of a causal link between the degree of alcohol abuse and qualification level of the respondents / V.Shapovalov, A.Gudzenko, V.Shapovalova, A.Osyntseva, V.Shapovalov. Pharmacia. 2017. Vol. 66, N. 3. P. 31-39.

3. Allott K., McGorry P., Yuen H., Firth J. The Vitamins in Psychosis Study: A Randomized, Double-Blind, Placebo- Controlled Trial of the Effects of Vitamins B12, B6, and Folic Acid on Symptoms and Neurocognition in First-Episode Psychosis. Biol. Psychiatry 2019; 86(1): 35-44. [Electronic resource]. URL: https://www.ncbi.nlm.nih.gov/pubmed/30771856. (Application date 05. 10. 2018).

4. Appetitive Aggression in Women: Comparing Male and Female War Combatants / D. Meyer-Parlapanis, R. Weierstall, C. Nandi, M. Bambonyé et al. Front. Psychol. 2015. N. 6. P. 1972-1979 [Electronic resource]. URL: https://www.ncbi.nlm.nih.gov/pmc/articles/PMC4700207. (Application date 05. 10. 2018).

5. ATC-classification. [Electronic resource]. Compendium on-line. URL: http://compendium.com.ua/atc. (application date 05. 10. 2018).

6. Evidence-based pharmacy: particularities of control regime for medicines with psychoactive attributes / V.A. Shapovalova, V.V. Shapovalov, V.V. Shapovalov, S.I. Zbrozhek, V.A. Radionova. Pharmacy of Kazakhstan. 2017. N. 6 (192). P. 30-35.

7. Experience of Great Britain in organization of healthcare system for pharmaceutical provision with medicines for privileged categories of citizens / V.V. Shapovalov (Jr.), V.O. Shapovalova, V.V. Andrieieva, V.V. Shapovalov. Health of society. 2019. Vol. 78, N. 1. P. 36-40. DOI: 10.22141/2306-2436.8.1.2019.172617. 